\section{Questión}

Periodismo / Comunicación ISSN 1669.6581

En primera persona. Ciudadanías comunicacionales en la experiencia de la FM Comunitaria La Voz Indígena

Mariana Ortega

Question/Cuestión, Nro.70, Vol.3, diciembre 2021

ISSN: $1669-6581$

URL de la Revista: https://perio.unlp.edu.ar/ojs/index.php/question/

IICom -FPyCS -UNLP

DOI: https//doi.org/10.24215/16696581e638

\title{
En primera persona
}

\section{Ciudadanías comunicacionales en la experiencia de la FM Comunitaria La Voz Indígena}

\section{In first person}

“Communicative Citizenships" in La Voz Indígena community radio.

\section{Mariana Ortega}

CONICET/ICSOH/Universidad Nacional de Salta

Argentina

marortega.012@gmail.com

\section{Resumen}

La FM Comunitaria La Voz Indígena es una radio pluriétnica, integrada por comunicadores de los pueblos wichi, guaraní, toba qom y chorote. Esta experiencia, ubicada en Tartagal (norte de la provincia de Salta) da cuenta de las complejas relaciones que los pueblos originarios entablan con el Estado. 
La emergencia de la comunicación comunitaria e indígena significó una profunda transformación en la vida de este colectivo. Construida para revertir la exclusión de las voces indígenas de los medios de comunicación locales, esta emisora logró configurar un espacio de representación propia, no solo para transformar estigmas sino fundamentalmente para afirmar la existencia indígena en el presente.

La sanción de la Ley de Servicios de Comunicación Audiovisual y el reconocimiento del derecho a la comunicación indígena, movilizó sentidos que nos instan a repensar la relación entre el Estado, la promoción de derechos y las resistencias indígenas.

En este artículo proponemos detener el foco en la interacción entre la comunicación indígena y el derecho a la comunicación, a partir del concepto "ciudadanías comunicacionales". Consideramos que el análisis de los efectos del reconocimiento de derechos en la vida contemporánea de los pueblos originarios, arroja perspectivas importantes para reflexionar sobre los movimientos indígenas y sus reivindicaciones de autonomía.

Palabras clave: ciudadanías; resistencias; comunicación indígena.

\section{Abstract}

La Voz Indígena community radio is a multi-cultural experience, formed by journalists from different indigenous peoples (Wichi, Toba qom, Chorote and Guaraní native nations). This radio, located in Tartagal (north of Salta), reveals the complex relationships that indigenous peoples set with the Argentinian State.

The emergence of community and indigenous communication as a specific kind of communication, meant a deep transformation for this group. This radio, were built to fight against racial discriminations, and also to elaborate a particular place where people can recognize its ethnic identity and dismantle prejudices.

In this article, we propose to analyze the way in which indigenous communication and right to communicate are related, in order to understand what "communicative citizenships" concept means. Consequently, this analysis offers new perspectives to reflect on indigenous movements and its rights recognitions claims. 
Key words: citizenships; fights; indigenous communication.

\section{Introducción}

La FM Comunitaria La Voz Indígena es una radio pluriétnica, integrada por comunicadores de los pueblos wichi, guaraní, toba qom y chorote. Esta experiencia, ubicada en Tartagal (norte de la provincia de Salta) además, nuclea al centro cultural de la memoria étnica Litania Prado y la organización de mujeres indígenas ARETEDE, la cual, a su vez, es la unidad que dirige a todos los espacios mencionados.

Geográficamente, Tartagal pertenece a la región central del Gran Chaco Sudamericano. Posee una población que, según estimaciones actuales, asciende a los 80 mil habitantes. La historia de esta ciudad remite al proceso de conquista y colonización de la zona, entre fines del siglo XIX y principios del XX (Rioja, 1997; Pojasi, 2013). Formalmente, fue creada como municipio en el año 1924.

Desde tiempos pre-conquista, esta región es habitada por los pueblos originarios wichi, guaraní, weenhayek, chorote, toba qom, chané y tapiete (Buliubasich y González, 2009). El proceso de conquista y colonización intensivo desde mediados del siglo XIX, movilizó transformaciones y rupturas en las vivencias contemporáneas de las poblaciones indígenas Principalmente, en la desposesión territorial (Iñigo Carreras, 2010) y en el desplazamiento a los suburbios de las localidades formadas bajo el dominio estatal, tal es el caso de Tartagal

La situación actual de las poblaciones indígenas está ligada directamente a los efectos de los sometimientos de la conquista. El empobrecimiento y las problemáticas de precarización de la vida, concretamente explicitadas en el mínimo acceso a derechos humanos básicos (agua, alimentación, vivienda, salud, territorios), encuentran en dicha base material un factor común.

En este contexto se inscribe la experiencia de La Voz Indígena, una radio comunitaria indígena pionera en la historia de los medios gestionados por pueblos originarios en la Argentina. Construida para revertir la exclusión de las voces indígenas de los medios de comunicación locales, esta emisora logró configurar un espacio de representación propia, no 
solo para transformar estigmas sino fundamentalmente para afirmar la existencia indígena en el presente, desde el dolor, pero también desde la esperanza de un nuevo porvenir.

En este artículo analizaremos la relación entre las prácticas discursivas de la comunicación comunitaria indígena y el ejercicio de las ciudadanías comunicacionales.

\section{Metodología}

El presente artículo reúne reflexiones surgidas de un proceso de investigación doctoral, el cual da cuenta de una perspectiva teórica interdisciplinaria. Metodológicamente, nos basamos en la genealogía, la eventualización y la etnografía como procedimientos de abordaje de la experiencia.

La perspectiva genealógica nos permitió historizar el caso de FM Comunitaria La Voz Indígena, valiéndonos de las contribuciones y propuestas de Michel Foucault (1980) para comprender la historia desde enfoques no lineales y suprahistóricos. Asimismo, esta postura de análisis, posibilitó el abordaje de la experiencia desde el reconocimiento de las disputas, desplazamientos y relaciones de poder que la constituyen.

En palabras de Foucault (2000), las genealogías son:

“[...] redescubrimiento meticuloso de las luchas y memoria bruta de los enfrentamientos [...] Llamamos pues "genealogía" al acoplamiento de los conocimientos eruditos y de las memorias locales: el acoplamiento que permite la constitución de un saber histórico de las luchas y la utilización de este saber en las tácticas actuales". (p. 22)

De este modo, la perspectiva genealógica constituye una herramienta de investigación, a través de la cual es posible "determinar las condiciones de emergencia, de irrupción, de aparición de un fenómeno determinado" (Sánchez Amaya, 2010, p. 100). Los abordajes genealógicos se proponen, entonces, comprender la emergencia de los fenómenos en un campo específico de relaciones de fuerzas. En este sentido, la emergencia designa un punto de surgimiento, una irrupción, un lugar de enfrentamiento (Foucault, 1979). Nuestro análisis, 
atendiendo a esta perspectiva metodológica, procura entender la singularidad del fenómeno, las condiciones y prácticas que lo constituyen como tal.

La atención puesta en el suceso nos aproxima a otro de los principales puntos que sostienen metodológicamente nuestro análisis; a saber, la eventualización. Para Restrepo (2008), la eventualización es una estrategia de abordaje y un procedimiento de análisis. Eventualizar un fenómeno implica atender a la emergencia de una discontinuidad, de una ruptura de evidencia.

Finalmente, para el trabajo de campo, empleamos la etnografía como método. A lo largo del proceso de investigación nos hemos involucrado activamente con el proyecto político de la emisora, por lo que la etnografía no solo constituyó un método o técnica de investigación, sino un proceso de "participación observante" (Becker y Geer, 1982) que transformó e interpeló continuamente la práctica de la investigación. Este artículo se sustenta, entonces, desde la participación, entendiendo, en palabras de Guber (2011), que "la participación es la condición sine qua non del conocimiento sociocultural" (p. 55).

El ejercicio de la investigación social es siempre un camino de tensiones y disputas que ponen en jaque a la relación sujeto/objeto de conocimiento. Este ejercicio incita a rechazar a adquirir tanto el modelo cartesiano de saber (que separa tajantemente a quien conoce de quien es desconocido) como la insistencia occidental en ir por aquello que se presenta y se construye como lo "otro". La práctica de la investigación en los territorios del norte de Salta se ejerce en ese entramado de relaciones de poder. Por lo tanto, nuestra investigación parte de reconocer la existencia de diferentes reflexividades (Hammersley y Atkinson, 1994) en tensión.

Además del trabajo etnográfico, la investigación se sustentó en la indagación del archivo de la organización. Éste corpus está compuesto por numerosos elementos, principalmente, por documentación de folletos, escritos, proyectos, cartillas formativas, afiches, videos y grabaciones de sonido que recopilan testimonios de los miembros de la organización. Así como también contiene aquellos libros que forman parte de la biblioteca, actas y documentos que pertenecen a la constitución jurídica del colectivo. 
Convocando la perspectiva foucaulteana, el trabajo de indagación archivística se relaciona con el abordaje genealógico de la historia del colectivo en estudio. En tal sentido, es importante aclarar que nuestra investigación no se enmarca en un proceso arqueológico de profundización en los discursos, sino más bien en la forma en que diferentes enunciados se inscriben en las prácticas que dieron paso a la emergencia y consolidación de una experiencia de resistencia.

Los archivos, desde nuestra perspectiva y siguiendo los aportes de la etnografía archivística, constituyen "transparencias en las que se inscriben relaciones de poder" (Stoler, 2010, p. 466). Para el abordaje de los archivos, este posicionamiento nos sugiere considerarlos en tanto procesos, tecnologías de producción de conocimiento y no meramente espacios de recuperación.

"El aire es libre, podemos hacer radio": condiciones de emergencia de la FM Comunitaria La Voz Indígena

Como hemos manifestado anteriormente, la experiencia de La Voz Indígena no constituye solo un medio de comunicación, su existencia se sustenta en la organización de mujeres indígenas ARETEDE y el centro cultural de la memoria étnica Litania Prado.

La emergencia de este colectivo de comunicación indígena se sitúa temporalmente entre fines de la década de 1990 y principios de los 2000, en la dinámica de una serie de acontecimientos y procesos fundamentales: la formación de ARETEDE (Asociación Regional de Trabajadores en Desarrollo), el desarrollo de los Talleres de Memoria Étnica y la realización de los Encuentros Departamentales de Mujeres Indígenas en el período 2000-2006. De esta manera, la radio emergió como consecuencia del trabajo previo de reflexión sobre las memorias étnicas de las mujeres indígenas y de la puesta en palabras de sus problemáticas y anhelos colectivos.

El importante rol de los Talleres de Memoria Étnica en el agenciamiento de este conjunto de personas, se articuló a partir de la posibilidad de narrar las historias de la conquista y colonización de los pueblos originarios del Gran Chaco, siendo un espacio para pronunciar memorias silenciadas y ocultadas. 
La experiencia de los TME incidió en la imbricación de la comunicación radial, las memorias y las identidades étnicas, en el marco de un proyecto político reivindicatorio de la etnicidad como posicionamiento de lucha contra las políticas de homogeneización cultural de la sociedad local. En consiguiente, la comunicación comunitaria encajó en este proceso, siendo el motor para dinamizar la puesta en práctica de la palabra indígena en proceso de liberación.

Entre 2002 y 2007 se realizó el programa radial titulado "La Voz del Pueblo Indígena" emitido por Radio Nacional Tartagal, y finalmente, en el año 2008, se inauguró la radio comunitaria La Voz Indígena. Tanto la puesta en marcha del programa como el logro de la radio propia, requirieron de un intenso proceso de capacitación y formación de comunicadores indígenas, etapa que contó con el apoyo de la carrera Comunicación Social de la Universidad Nacional de Salta Sede Regional Tartagal.

Consideramos que la emergencia del proyecto comunicacional marcó una ruptura en el rumbo de este colectivo, debido a que habilitó la formación de un oficio concreto, el de comunicadores; al impacto generado en el contexto local por la visibilización e irrupción de voces indígenas en el espacio mediático; y a la posibilidad de canalizar los dolores, reclamos, padecimientos a través de la palabra, dando así paso a un proceso de reparación y de organización del discurso colectivo, en torno a la proclama "somos las voces de la resistencia indígena".

\section{Las voces de la resistencia indígena: prácticas discursivas y una agenda de los pueblos originarios}

Las radios son medios de comunicación que adquieren gran importancia en contextos rurales, tal es el caso de Tartagal. Si bien esta localidad es definida como una ciudad, su alcance geográfico se extiende a grandes porciones de territorios rurales, habitados mayormente por pueblos originarios. La facilidad de acceder a un dispositivo radial, y la amplia cobertura espacial que caracteriza a las radios, hacen que estos medios de comunicación cumplan un rol central en las dinámicas territoriales: en la circulación de la información, en el entretenimiento y en el contacto con otras comunidades e instituciones estatales. En esos contextos, las radios son actores importantes, además, en la formación de la opinión pública 
local. La incidencia de La Voz Indígena se circunscribe a las condiciones territoriales mencionadas, en las que sobresale por tratarse del único medio indígena de la zona.

Luego de haber mencionado estas características, nos proponemos indagar en la configuración del medio de comunicación desde su faceta discursiva. Entendemos que la radio, tal como afirma Mata (1993) constituye una práctica significante, una relación comunicativa y un espacio de compleja interacción y vínculo entre emisores, receptores y medios. En palabras de la autora, la radio "se convierte en espacio clave (como los restantes medios masivos) para la constitución de identidades individuales y colectivas a través del juego de múltiples interacciones (p.13).

Partiendo de esta perspectiva, nos preguntamos: ¿cómo se constituyeron las "voces de la resistencia indígena" en el tejido de la radio? Para dar cuenta de las características que adquiere la resistencia como práctica discursiva, nos centraremos en la construcción de la agenda de noticias de la emisora y los criterios de noticiabilidad empleados, en lo que Lamas y Villamayor (1998) denominan "perspectiva político-comunicacional" (p. 20).

Las discusiones en torno a los conceptos de comunicación comunitaria, alternativa, popular convocan posicionamientos diversos (Graziano, 1980; Kejval, 2009; Mata, 2011b; Vinelli y Rodríguez Esperón, 2008) que se han complejizado aún más con los diálogos y tensiones planteadas por las emergencias indígenas (CCAIA, 2010; Agurto y Mescco, 2012; Doyle, 2013; Lizondo, 2015; Herrera Huérfano, Sierra Caballero, Rojas, 2016; Barranquero y Sáez, 2015). Sin entrar en los debates profundos sobre las caracterizaciones de los medios comunitarios, alternativos, populares o indígenas, tomamos lo dicho por Vinelli (2014) quien alega la necesidad de revertir la noción de "esencia" por la de proceso, y partir de los consensos que conceptualizan a este tipo de comunicación:

"como aquella comprometida con los intereses de las clases y grupos populares, cuya finalidad no se agota en sí misma, sino que es parte de un proyecto de transformación y construcción de contrahegemonía que le da sentido y orientación, y que compone otro modelo de sociedad; que surge y se desarrolla a partir de la necesidad de recuperar la palabra, el acto afirmativo del habla, y por tanto para dar visibilidad a las voces silenciadas o tergiversadas por los medios hegemónicos [...] 
Que construye su agenda a partir otros criterios de noticiabilidad y de relación con los protagonistas, dando lugar a un discurso periodístico de contrainformación”. (p. 17)

La Voz Indígena conformó un corpus estético-discursivo entramado a partir de los relatos de la memoria étnica. Piezas radiales como los radioteatros "Gritos del destierro: voces del cacique Cambá" (2011) y "Woho Tenek". Ocasos del pasado. Historias de la conquista del pueblo Wichi" (2015) evidencian la estrecha relación entre las memorias y la comunicación radial.

La incidencia de los relatos surgidos de los talleres de memoria se evidencia en la definición de la identidad de la emisora bajo el lema: "somos las voces de la resistencia indígena". Esta proclama se conecta con la valoración de la radio como una práctica de lucha por parte de los propios comunicadores. Por ejemplo, una de las directoras del medio, afirma:

"En ninguna radio están acompañándonos, en ningún medio se habla de las verdades que pasan. En cambio, la radio que tenemos estuvo acompañando. No solamente acompañar, porque los comunicadores que estábamos en la radio, estábamos ahí. Si hay un conflicto nosotros lo sentimos, lo sufrimos. Los comunicadores sentimos, nosotros ponemos el cuerpo ahí. Entonces me parece una radio diferente, como los comunicadores son de las comunidades y son los que sufrimos. Entonces me parece una tarea muy importante porque sentir el maltrato o los golpes y estar frente a un micrófono, hablar sobre la situación, por ahí a veces a uno le tiembla la voz. ¿Por qué? Porque este cuerpo es el que siente los golpes, los maltratos. En la lucha de Quebracho la radio tuvo un rol muy importante porque estaba ahí. Por ahí, a veces, decimos nosotros, la lucha está en la radio. Pero también la radio está siempre, porque los comunicadores que somos de la radio La Voz Indígena siempre estamos en la lucha y la lucha también está en la radio (sic)". (Entrevista realizada por la autora, 2019)

Para el análisis de la dimensión informativa, resulta imprescindible mencionar que ésta se relaciona íntimamente con la definición política "ser una radio de lucha" que se manifiesta a nivel discursivo, específicamente, en la faceta relacionada al tratamiento de los hechos cotidianos de las comunidades indígenas y sus problemáticas históricas -entre ellas, los 
conflictos territoriales, la falta de alimentos, la violencia de las instituciones, la discriminación, los desmontes, la contaminación, etc.-. De esta manera, nos introducimos en la construcción de las noticias, los criterios de selección que operan en ellas y la configuración de una agenda de noticas sobre las problemáticas de los pueblos originarios de la zona.

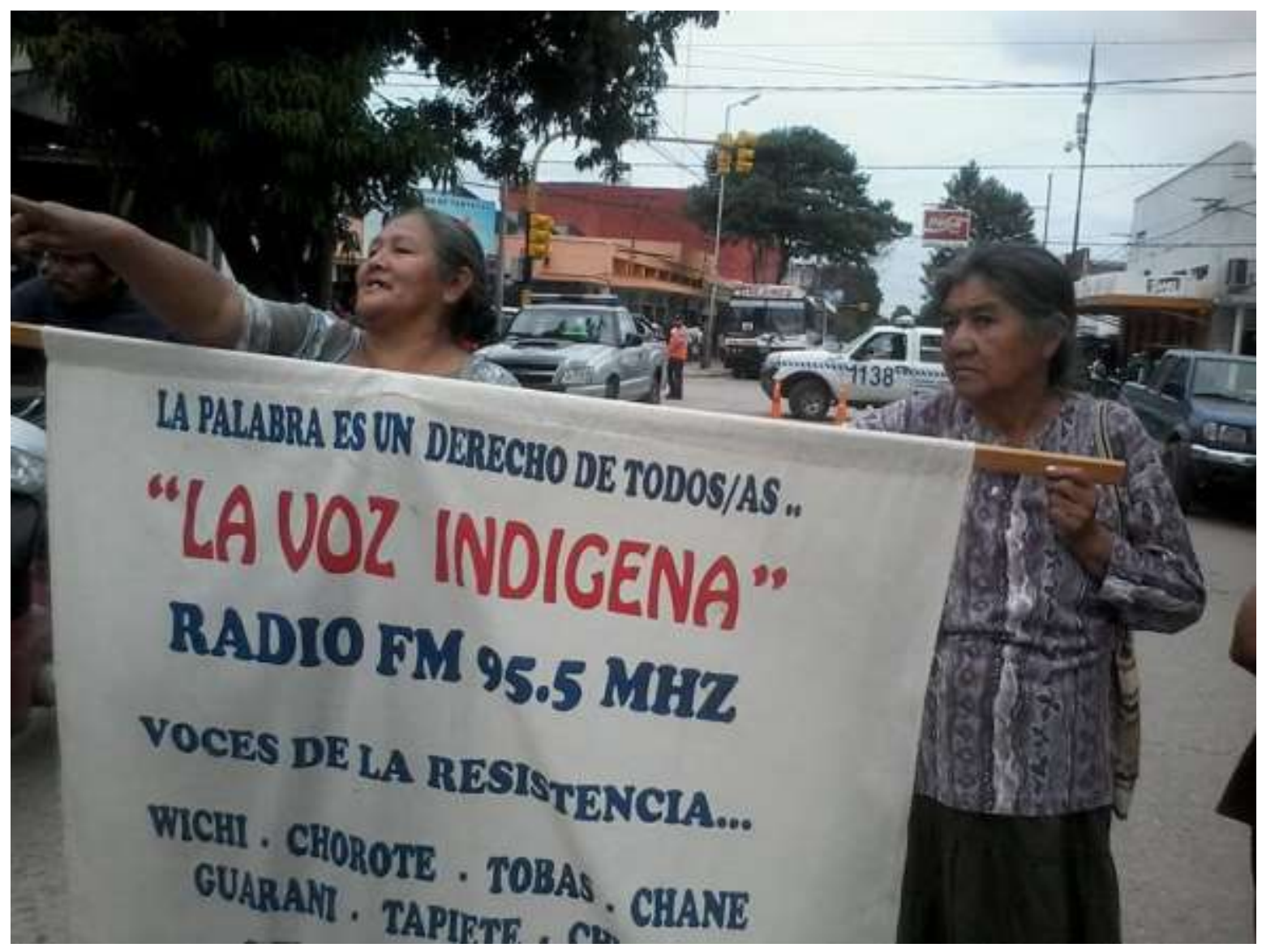

Figura 1: Marcha contra el desalojo de la comunidad Quebracho, 2014. Fondo de Archivo ARETEDE. (ARETEDE, Tartagal)

Es socialmente recurrente la afirmación de que los medios actúan y disponen noticias y coberturas de determinados temas en función de sus intereses políticos y económicos. A partir de ello, la apariencia de neutralidad y objetividad de los medios, hoy, se traduce en 
posicionamientos y opiniones múltiples sobre los hechos de la realidad e, incluso, se reviste de fabricaciones insólitas sobre determinados acontecimientos, tal es el caso de las fake news.

Puntualmente, nos interesa destacar que la capacidad de acción de los medios en la construcción de representaciones es amplia. De esto deriva una serie de operaciones sobre los fenómenos sociales, puntualmente, el recorte o recuadro de la realidad, la selección de hechos de la cotidianeidad, los criterios que utilizamos para ello y cómo los presentamos ante el público.

En el caso de las radios comunitarias, estos procedimientos tienen ciertos resguardos, ya que la construcción de la información se enmarca dentro de un conjunto de principios políticos que responden a un colectivo o sector de la sociedad, con necesidades informativas específicas. Esto diferencia a este tipo de medios de, por ejemplo, los comerciales, los cuales, si bien tienen perfiles políticos claros, se orientan a la población en general y de manera homogénea.

En relación al medio analizado, la definición de un colectivo y/o sector no significa limitar el público, el tratamiento de noticias y el alcance de la radio. Se trata más bien de una manera de obrar, que antepone los intereses del colectivo gestor del medio -en tanto representante de un sector de la población y sus necesidades informativas- a las necesidades del resto de la sociedad. En el caso de La Voz Indígena, el recorte de la realidad y los criterios de noticiabilidad están mediados por los intereses del colectivo y del sector al que pertenecen. Explícitamente, se centran en la figura de los pueblos originarios, sus problemáticas $\mathrm{y}$, de modo más puntual, en las resistencias y luchas indígenas.

Siguiendo a Martini (2000), las noticias pueden ser concebidas como aquellas construcciones periodísticas que se elaboran sobre un acontecimiento. Como vemos, son derivadas de un proceso constructivo en el que operan ciertos criterios. Desde la teoría del newsmaking o de "construcción de la noticia" se indica que éstas son:

"producto de la selección y el control, y de las formas de procesamiento que responden a "instrucciones" (más o menos explicitadas) de la empresa y a actitudes y valores consensuados o al menos aceptados (la distorsión consciente) y de la 
articulación de prejuicios, valores compartidos con el medio y con la sociedad". (Martini, 2000, p. 77)

En consecuencia, en la construcción de las noticias intervienen valoraciones que responden a las subjetividades de los comunicadores y a la perspectiva política que asume el medio. Todos estos elementos se ajustan a criterios de noticiabilidad definidos como "un conjunto de condiciones y valores que se atribuyen a los acontecimientos, que tienen que ver con órdenes diversos $(\ldots)$ formulaciones pragmáticas, modalidades organizativas del trabajo cotidiano" (Martini, 2000, p. 85).

Por su parte, estos modos de valorar actúan durante todo el proceso informativo mediático en función del "valor de la noticia como información práctica, como impacto emocional y como formadora de opinión pública" (Martini, 2000, p. 86). Es fundamentalmente, a través de estas valoraciones que se hace visible qué es lo importante, qué voces se privilegian, qué temáticas son más relevantes, qué tratamiento recibe cada hecho y cuál es su magnitud.

Atendiendo al caso de la radio comunitaria La Voz Indígena, los modos de valorar se ajustan a los principios de inclusión y exclusión que el colectivo define en función de sus objetivos, que, como hemos dicho, se articulan en torno a la identidad y las resistencias indígenas.

Vemos de este modo cómo la caracterización de los medios comunitarios, a partir de su vinculación con un sector específico de la sociedad, incide en que sus agendas mediáticas se relacionen íntimamente con el territorio. En relación a ello, Cerbino y Belloti (2016) afirman que "el vínculo con el entorno social y territorial se traduce en una definición de la agenda fuertemente anclada a lo territorial, es decir a las cuestiones culturales, políticas y sociales cercanas" (p. 54). Este rasgo es visible en La Voz Indígena y asume un modo sumamente enfático durante las coberturas y acompañamientos a aquellas comunidades desalojadas, como veremos a continuación.

Particularmente, en cuanto al tratamiento de noticias, nos abocaremos a dos casos muy importantes para la historia de la radio: el desalojo de la comunidad wichí/weenhayek Quebracho y la historia de la comunidad guaraní Yariguarenda. 
La comunidad guaraní Yariguarenda ("lugar de sapos") se encuentra ubicada a 11 kilómetros de la ciudad de Tartagal. Los primeros indicios de la colonización de toda la zona que comprende el departamento San Martín y, en particular Tartagal, refieren a Yariguarenda como un sitio de particular interés por su belleza paisajística, pues está dotada de selvas y arroyos, pero principalmente posee cualidades de gran valor para la extracción de petróleo y madera.

De acuerdo a la historia comunitaria de los habitantes guaraníes, esta comunidad ha sido objeto de intervenciones extractivistas desde 1911, a partir de la llegada de la empresa petrolera Standard Oil Company. Este hecho marcó el inicio del desarrollo de diversos emprendimientos extractivos, entre los que se destacan la explotación forestal de las serranías y las plantaciones de soja (Fondo de Archivo ARETEDE, 2020).

Ya hacia finales de 1990, las familias indígenas comenzaron a sufrir amenazas de desalojos, intimaciones e incluso ordenes de intervención de la policía, razón por la cual la comunidad inició un proceso de organización territorial. Éste llegó a ser uno de los casos que sustentó la sanción de la Ley de Ordenamiento Territorial №26.160, en 2006.

En este proceso de lucha, la comunidad enfrentó varios litigios, por un lado, contra una empresa sojera que había usado los territorios como garantía de una hipoteca, por otro, contra pobladores criollos y contra la iglesia católica -que administra el santuario Virgen de la Peña, ubicado en el mismo territorio-. Si bien la comunidad logró obtener, fruto de la movilización y la lucha, la personería jurídica, la cual reconoce la ocupación ancestral de las tierras y le otorga propiedad comunitaria, en la actualidad, todavía, se enfrenta a varios litigios judiciales.

Para la radio, la historia de esta comunidad ha sido de gran importancia. Yariguarenda representa un territorio de disputa simbólica y social, en el que se condensa el sentido fundacional civilizatorio de la ciudad de Tartagal. La disputa simbólica referida está presente, por ejemplo, en la forma de denominar al territorio ya que, con el paso del tiempo, el nombre de origen guaraní fue borrado y, hoy, se utiliza mayormente la denominación "Virgen de la Peña". Este ocultamiento simboliza el avance de las instituciones eclesiásticas sobre la identidad indígena del lugar. 
Particularmente, la radio comunitaria La Voz Indígena ha dado cobertura a todo el proceso de lucha de la comunidad, siendo impulsora colectiva de la resistencia territorial. Con ese objetivo han profundizado en la historia comunitaria, generando contenidos radiales de investigación, reivindicando así la constitución de una voz propia, la de los pueblos originarios. En el siguiente fragmento podemos leer y escuchar parte del documental radiofónico que narra el proceso de resistencia de la comunidad ante los diferentes intentos de desalojo a los que se enfrentaron a lo largo de su historia:

"El tema de la tierra era el tal XXX, el que se hacía el fuerte, el que venía y se hacía el dueño, el propietario de la tierra, que él había comprado, toda esta parte que nosotros ocupamos decía que era de él, y decía que nosotros teníamos que salir de aquí, que teníamos que ir a otro lado. $Y$ de aquí se han ido gente a vivir a Tranquitas porque él los ha sacado, y así el hombre, un tal XXX, nos quería sacar, y a nosotros nos amenazó que él iba a mandar la policía, que iba a mandar una máquina, a voltear la casa de nosotros, y yo le dije que no iba a salir, que yo era viviente de aquí y que no iba a sacarme de este lugar. Y yo le digo bueno, si él quiere traer la policía, la máquina, que traiga, que yo los iba a esperar aquí [...]Y después nos enteramos que él debía mucha plata al banco porque se prestaba plata del banco, entonces el banco le embargó la finca (Yariguarenda) y los tractores que él tenía. Después el banco puso en venta la finca. Entonces después vino la firma Fanegas, y de ahí comenzó mi suegro Valdés a ver cómo se podía solucionar el tema tierras [...] ¿Por qué ellos dicen que son dueños de todo acá? Entonces es la viveza también. Parece que antes agarraban y decían esto es mío y directamente usaban la violencia. Es por eso que la mayoría de la gente le tenía miedo, muy agresivo ese hombre, me decía que esas tierras eran de él. Nosotros siempre tuvimos problemas con las tierras, de a poco nos han ido arrinconando el lugar, llevándonos, quitándonos espacios. Primer problema que surgió fue cuando nos enteramos que la finca Yariguarenda había sido rematada y la habían comprado unos sojeros, y esos sojeros no sabían que había una comunidad aquí. Cuando ellos vinieron acá a querer desmontar se dieron con que nosotros estábamos acá, e hicieron todos los legajos para desalojarnos y mi papá, él se opuso al desalojo, porque la orden ya estaba. Teníamos tres días para hacer el descargo y presentar un abogado como para que haga la defensa, y bueno, se logró frenar ese desalojo, pero 
ya habían llegado a un acuerdo. Como mi papá no era tan para hablar y como para hacer un buen negocio, bueno, a él le han ofrecido trece hectáreas, y él agarró, y trece hectáreas para una comunidad no es nada. Las trece hectáreas están en cerca de la quebrada, las tierras no sirven para cultivar porque están llenas de arena, o sea que de todo lo que nosotros teníamos, nos han reducido a nada el espacio en el que vivimos y para cultivar no nos ha quedado nada, y todo para cercar, una buena parte ha sido desmontada, otra buena parte ha sido para sacar madera, se han cortado los árboles". (Fondo de Archivo ARETEDE, 2012) (1)

El seguimiento y la activa participación de la radio durante toda la historia de lucha de la comunidad, radica también en que los integrantes de la misma son parte del colectivo. Tal es el caso de la mburuvicha (autoridad) de la comunidad, quien es comunicadora de la radio. Por ejemplo, en el año 2019, en ocasión de una de las agresiones a la comunidad, la cacica se refiere a la cobertura mediática hecha por un canal de televisión, en especial una periodista, quien había afirmado que los integrantes de la comunidad estaban vendiendo terrenos:

"Y también a la periodista de un canal de Tartagal, la cual dijo todo lo contrario, la mentira porque ella tenía que tener como prueba para hablar de lo que estaba diciendo digamos en la noticia, así que le digo algo a la periodista es de público conocimiento esta denuncia porque ella estuvo hablando sin ninguna prueba. Así que todo lo que ella dice no es la versión de la comunidad. Así que bueno, ella para informar tenía que haberse llegado y ver la otra parte, en qué situación se encuentra la tierra (sic)". (Fondo de Archivo ARETEDE, 2019)

El caso de Yariguarenda y las acciones realizadas para disputar un territorio simbólicamente complejo evidencian la trascendencia de la radio para los sujetos que la construyen y el rol de las mujeres en las manifestaciones de resistencia. Se referencia, asimismo, tanto las omisiones de los medios comerciales a los reclamos y manifestaciones indígenas, como el tratamiento sesgado y estigmatizante que reciben estos hechos cuando se convierten en noticias. Por tanto, resultan indicativos de la mirada y acción política sobre la opinión y la construcción de estereotipos sobre los pueblos originarios, pues desprestigian sus causas sin ningún esfuerzo por comprenderlas históricamente. 
En lo referente al caso de la comunidad wennhayek Kyelhyuktaj (Quebracho), ésta se encuentra ubicada sobre los márgenes de la ruta nacional 86, a cinco kilómetros de la ciudad de Tartagal. Dicha ruta es un espacio en el que convergen, por un lado, numerosas comunidades originarias, principalmente de los pueblos wichí, toba y chorote. Por otro lado, en ella, existen grandes fincas y empresas dedicadas a la extracción de madera y a la plantación de soja, maíz y otros monocultivos.

En noviembre de 2014, la comunidad Quebracho fue desalojada violentamente por la policía, como consecuencia del litigio judicial iniciado por una empresaria de la ciudad de Tartagal, titular registral de la propiedad. El desalojo fue un hecho de gran impacto por el accionar violento de las fuerzas de seguridad, las cuales ingresaron a la comunidad a sacar las pocas pertenencias y a destruir las precarias viviendas de sus habitantes. Debido a la golpiza y a los hechos traumáticos vividos, una anciana falleció luego del desalojo. Por su parte, la comunidad se mantuvo en protesta durante varios meses, realizó cortes de ruta y enfrentó en varios episodios situaciones de acoso policial. Se realizaron marchas por las calles de Tartagal, exigiendo justicia. En la actualidad, la comunidad vive en el mismo lugar, aunque rodeada de plantaciones de soja y otros sembrados, a la espera de la resolución judicial.

La participación de La Voz Indígena en estos hechos nos permite analizar el modo en que la radio da tratamiento a este tipo de problemáticas. Al igual que en el caso de Yariguarenda, los integrantes de la comunidad en cuestión son activistas e integrantes de la emisora. Es por este motivo que el colectivo indígena se involucró activamente tanto en la cobertura de los hechos a través del medio de comunicación, como en la organización de acciones de protesta.

El relato de N.L., mediatizado por La Voz Indígena, en ocasión de una de las marchas por las calles de Tartagal, expresa lo siguiente:

"Estamos en este momento frente a la casa de nuestras autoridades. Hoy es un día muy especial, de una ley muy importante para nosotras las mujeres. ¿A dónde están nuestras autoridades, nuestros caciques, nuestros dirigentes? ¿dónde están? Estamos en lucha hace diecisiete días, estamos ahí, a la orilla de la ruta, durmiendo. A la noche no podemos dormir, algunos en vigilia todas las noches, con miedo. Los niños 
están inseguros en ese lugar, ya que hay muchas víboras venenosas en ese lugar. ¿Por qué no nos escuchan? Ya estamos cansados, estamos ahí durmiendo en el suelo, no tenemos frazada, no tenemos nada, estamos esperando una respuesta, estamos esperando a nuestras autoridades. ¿Dónde están? Están ahí escondidas nuestras autoridades. El pueblo originario está marginado, décadas están clamando, el pueblo originario está luchando, han pasado muchas décadas y todavía estamos sufriendo. Han pasado años y hoy estamos sin techo, estamos acampando en la intemperie de una orilla de la ruta 86 , niños sufriendo, los niños que han perdido una madre están ahí, desprotegidos [...] ¿Dónde están nuestras autoridades, dirigentes?, ¿por qué no nos escuchan? Hasta cuándo vamos a estar sufriendo como pueblos originarios cuando hay una ley que nos ampara, y esas leyes ¿se han enterrado?, ¿no están vigentes esas leyes?, ¿están pisoteadas esas leyes? [...] Estamos todavía en pie, estamos esperando, siempre esperando pacientemente, sin levantar, sabiendo que también somos luchadores. Sabemos lo que es luchar, pero no luchamos con violencia. No estamos aquí para hacerle daño a nadie, sino estamos esperando respuestas, estamos esperando años respuestas, que nos devuelvan lo que hemos perdido (sic)". (Fondo de Archivo ARETEDE, 2014) (2)

La agenda de noticias y la forma en qué se produce la realidad desde La Voz Indígena nos inducen a reflexionar sobre las prácticas de ciudadanía en los intersticios del derecho y la performatividad de la palabra. Es por eso que proponemos profundizar en la noción de ciudadanías comunicacionales (Mata, 2006) y las ramificaciones de este concepto en las relaciones complejas entre el Estado y los pueblos originarios.

\section{Ciudadanías comunicacionales y comunicación comunitaria}

La influencia del derecho en las sociedades contemporáneas es un tema recurrente en los intereses académicos y, especialmente, en los estudios de comunicación social. En Argentina, la sanción de la Ley de Servicios de Comunicación Audiovisual (LSCA) en el año 2009, significó un cambio de paradigma en el sistema mediático y comunicacional (Baranchuk, 2009). El reconocimiento del derecho a la comunicación y la comunicación definida como un servicio público, fundamentos de la ley, cimentaron la implementación de diferentes estrategias para garantizar el ejercicio igualitario de este derecho. 
La posibilidad de sumar prestadores al sistema mediático, habilitada por el reconocimiento de nuevos actores, entre ellos: los medios comunitarios, las universidades y los pueblos originarios, favoreció la democratización de los espectros mediáticos. Específicamente, en el caso de los pueblos originarios, la LSCA, basándose en la naturaleza jurídica constitucional que reconoce su preexistencia étnica, los definió como personas de existencia ideal de derecho público estatal. Por lo tanto, al igual que las universidades y la iglesia católica, el otorgamiento de licencias se realiza mediante autorizaciones a demanda directa.

La naturaleza jurídica constitucional de los pueblos indígenas motivó, entonces, que fueran categorizados como sujetos particulares. Este hecho propició debates en torno al concepto de comunicación indígena, puesto que una de las razones para disputar el reconocimiento de la especificidad de los medios de pueblos originarios, fue el rechazo a ser considerados bajo la denominación "medios comunitarios".

Sin adentrarnos en estas discusiones, nuestro análisis se focaliza en la relación entre el derecho a la comunicación y las ciudadanías comunicacionales en el caso de la radio comunitaria La Voz Indígena. De esta manera, es importante retomar la relación entre la posesión de derechos y la ciudadanía bajo la condición "sujeto de derechos". En tal sentido, nos preguntamos: ¿qué efectos generó el derecho a la comunicación en la experiencia? y ¿cómo impactó en la conformación de prácticas de ciudadanía?

Respecto a la relación entre ciudadanía y comunicación, nos basamos en los aportes de Mata (2002, 2006, 2009, 2011a; 2011b), quien se pregunta por el vínculo entre la comunicación y la representatividad política en los escenarios multimediáticos y, particularmente, por el desempeño de los medios comunitarios y en la generación de prácticas constituyentes de ciudadanía.

Desde este panorama analítico, la pregunta por la ciudadanía retoma el problema de la representación política. En una de sus tesis, Mata (2002) considera que la íntima relación entre los medios de comunicación y la ciudadanía ha promovido la aparición de un modo específico de ser en el mundo, el cual es definido como "[...] de aparición de los individuos en el espacio público, caracterizado por su capacidad de constituirse como sujetos de demanda y proposición en diversos ámbitos vinculados con su experiencia: desde la nacionalidad y el 
género hasta las categorías laborales, y las afinidades culturales" (p. 66). Es en función de este planteo que los medios son concebidos por Mata (2002) como espacios realizadores de ciudadanía, de representación política de los ciudadanos, y la comunicación es, en ese sentido, condición de posibilidad de ciudadanía:

"La comunicación se reconoce como fundante de la ciudadanía en tanto interacción que hace posible la colectivización de intereses, necesidades y propuestas. Pero, al mismo tiempo, en tanto dota de existencia pública a los individuos visibilizándolos ante los demás y permitiendo verse -representarse ante sí mismos. Ese reconocimiento de la comunicación como condición de posibilidad de la ciudadanía es, al tiempo, condición de posibilidad de la política". (p. 67)

Siguiendo esa perspectiva, la autora plantea la noción de "ciudadanía comunicativa", a partir de la profundización de su idea de ciudadanía asociada a la emergencia de un nuevo modo de aparición de los sujetos en los espacios públicos. En relación a esto, existen ciertas maneras de ser ciudadano en los medios de comunicación: el ciudadano sujeto de necesidades, sujeto de demandas y sujeto de decisiones. Como conclusión de sus indagaciones, Mata (2006) conceptualiza la noción de ciudadanía comunicativa, la cual remite al:

"Reconocimiento de la capacidad de ser sujeto de derecho y demanda en el terreno de la comunicación pública, y el ejercicio de ese derecho. Se trata de una noción compleja que envuelve varias dimensiones y que reconoce la condición de público de los medios que los individuos tenemos en las sociedades mediatizadas. La noción de ciudadanía comunicativa remite necesariamente a derechos civiles - la libertad de expresión, el derecho a la información [...] En este sentido, y como ocurre en general con los derechos civiles, la ciudadanía comunicativa representa un límite a la acción del Estado con el fin de garantizar la libertad de las personas y representa un estatus jurídico". (p. 13)

Para la autora, el ejercicio de la ciudadanía comunicativa es fundamental para las sociedades de ciudadanos debido a que se entrelaza con los reclamos identitarios y con las causas que buscan igualdad. A su vez, presenta distintas dimensiones: 
"Uno es el nivel de la "ciudadanía comunicativa formal", representada por el conjunto de individuos depositarios de derechos consagrados jurídicamente en el campo comunicativo. Pero otro, es el que denominamos "ciudadanía comunicativa reconocida", es decir, la condición de quienes conocen tales derechos como inherentes a su condición de integrantes de una comunidad determinada. $Y$ otra es la "ciudadanía comunicativa ejercida", reconocible en quienes desarrollan prácticas sociales reivindicatorias de dichos derechos, en pos de su vigencia y/o ampliación". (Mata, 2006, p. 14)

Tanto los niveles como los tipos de ciudadanía en los medios de comunicación tienen en común el reconocimiento de la existencia de actores en pugna y tensión, "quienes tratan de obtener, usufructuar y ampliar derechos, quienes tienen el poder legítimo y/o legal de concederlos y quienes obstaculizan, pervierten o restringen tales derechos" (Mata, 2006, p. 14).

A partir de lo expuesto, vemos que la noción de ciudadanía comunicativa nos propone pensar el ejercicio del derecho a la comunicación desde la pugna y el conflicto, desde la dinamicidad del acto de comunicar públicamente y contraponerse a los efectos del poder. Esta lectura, en primera instancia, parte de la noción de derecho para pensar la ciudadanía, pero también, insta a reflexionar sobre las posibles incidencias que la relación derecho/ciudadanía/medios de comunicación puede generar.

Indagar en la interrelación entre sujeto de derechos y ciudadano, nos acerca a la revisión de aquellas concepciones que reducen la ciudadanía a la portación de derechos y, a la vez, engrandecen la figura del ciudadano como un sujeto plenamente emancipado y capaz de decidir por sí mismo e injerir en las decisiones públicas. Estas lecturas sesgadas de optimismo no contribuyen a reflexionar sobre las complejas implicancias del derecho y la ciudadanía en las sociedades contemporáneas. En relación a esto, vemos que ser sujeto ciudadano portador de derechos es leído críticamente por quienes consideran que esta noción constituye un invento moderno de homogeneización de identidades, especialmente, en el contexto diverso de América Latina. Asumiendo esta mirada, Santiago Castro Gómez (2000) afirma:

"La formación del ciudadano como "sujeto de derecho" solo es posible dentro del marco de la escritura disciplinaria y, en este caso, dentro del espacio de legalidad 
definido por la constitución. La función jurídico-política de las constituciones es, precisamente, inventar la ciudadanía, es decir, crear un campo de identidades homogéneas que hicieran viable el proyecto moderno de la gubernamentabilidad". ( $p$. 90)

A pesar de las diferentes posiciones sobre un término tan polémico -como lo es el de ciudadanía- asumimos de modo certero que las sociedades actuales gestionan y organizan sus gobiernos estatales a través de sistemas de derechos y estos son considerados, también, recursos de defensa de movimientos sociales, organizaciones, colectivos etc. Afirmamos, asimismo, que la ciudadanía es una noción moderna y, si bien no procede de América Latina, ello no quita la posibilidad de indagar en sus efectos.

Tomando como referencia a Foucault (2010) respecto al derecho y la necesidad de superar dicotomías excluyentes, coincidimos en que el derecho ha sido una estrategia de gobierno moderna, pero que sus incidencias no deben reducirse a la simple dominación -tal análisis recae en posturas apocalípticas-. Es así que entendemos que el derecho es una de las vías de acción sobre las poblaciones, pero no la única. Consideramos que, en el caso de La Voz Indígena, el derecho a comunicar aparece como un poliedro de inteligibilidad, con muchas caras y posturas de las que emergen posiciones variadas de acuerdo a los escenarios de lucha. Desde la particularidad del proceso estudiado, el derecho a la comunicación se presenta como un umbral de apertura a otros derechos, en un campo de permanente negociación y transacción.

Bajo esta lectura, el derecho a la comunicación exhibe características transaccionales, en la medida en que parte de la propia práctica gubernamental y, también, se constituye como "el efecto de una transacción que separa, por un lado, la esfera de intervención del poder público y, por otro, la esfera de independencia de los individuos" (Foucault, 2010, p. 61). De este modo, el derecho a la comunicación delimita un espacio de independencia en el que el "decir" no es un recurso "cedible", al contrario, es quizás el único espacio de libertad posible. Tal derecho -importante para la democracia- resguarda la libertad de expresión y no se garantiza con la simple proclamación; al contrario, es necesario batallar para que se pueda ejercer. Éste es el caso de Argentina y el difícil proceso de sanción e implementación de la LSCA. 


\section{Conclusiones: de ser enunciadxs por terceros a la práctica de la auto-enunciación}

El camino construido por los comunicadores de La Voz Indígena da cuenta de una historia de lucha contra los sometimientos coloniales que persisten en el presente; en diferentes facetas, este colectivo supo configurar una experiencia de pronunciamiento de memorias silenciadas y ocultadas.

Hemos visto cómo este colectivo constituye un caso pionero en la lucha de los pueblos originarios por el derecho a la comunicación, a la vez que su existencia se vio dinamizada por los planteos de la LSCA, específicamente, desde el reconocimiento de los pueblos originarios como sujetos prestadores de servicios de comunicación audiovisual.

La mirada al derecho a la comunicación se complejiza desde las intersecciones que anteponen la palabra en circulación a la perspectiva jurídica. Entendemos que el caso de La Voz Indígena nos muestra, retomando a Mata (2011) cuando afirma que "no cualquier práctica enunciativa tiene la potencia de configurar la presencia desde la ciudadanía, sino aquella que fuerza las barreras de la comunicación" (p. 5) que las ciudadanías comunicacionales trascienden el sentido tradicional de la posesión de derechos.

Las ciudadanías comunicacionales, en este caso, evidencian la presencia de una sinergia entre el pronunciamiento, la representación, la visibilidad y la identidad étnica. Este complejo entrecruzamiento abre paso a un modo de existencia y de aparición en los medios de comunicación, que no se reduce a la visibilidad, sino a la puesta en práctica de posicionamientos de disputa y lucha contra los intentos de ordenamiento estatal y no estatal, destinados a designar y ubicar a los indígenas en determinados roles subalternos.

Entendemos así, que las ciudadanías comunicacionales en La Voz Indígena son prácticas de reivindicación de una forma de ser sujeto en el presente. La proclamación de las palabras antes ocultadas, y pronunciadas por personas históricamente discriminadas, significó desandar un proceso de re-configuración de las identidades, dando cuenta, siguiendo a Mata (2006), del acto de "recuperar una posibilidad mutilada y perder el miedo a hacerse ver exhibiendo los mismos rasgos que determinaban su exclusión" (p. 6). 
Desde estas interpretaciones, podemos ver cómo La Voz Indígena y los comunicadores recuperaron la palabra mutilada por la experiencia de la conquista y las violencias del presente. Desde allí, configuraron un proceso de rearmado de la palabra en base a luchas pretéritas y resistencias actuales. La comunicación comunitaria dio paso a una experiencia intempestiva en la que la práctica del "ver y hacerse oír" se ejerce desde el forzamiento de las barreras de la comunicación.

Desde esta línea argumental, los comunicadores de La Voz Indígena llevaron la palabra al límite y desde allí, disputaron y se rebelaron contra el silencio, incomodando a los oyentes y a la sociedad que no habla de ciertos temas: desalojos, discriminaciones, violencias raciales; todas estas cuestiones sepultadas e inexistentes en la esfera pública de la agenda mediática. En relación a ello, hablar de las usurpaciones en Yariguarenda, disputar el territorio a quienes dominan el discurso católico de la zona, marchar por las calles, resistir desalojos fueron acciones que posicionaron a los comunicadores como cuerpos rebelados, anormales e insurgentes. Es así que el paso y quiebre de la invisibilidad a la visibilidad no fue un hecho ligado solo al acto de hablar en un medio.

Los comunicadores indígenas no formaron parte de un medio como un hecho aislado, sino que lo hicieron en el marco de una organización de lucha que tenía como objetivo disputar la función homogeneizante y excluyente de los medios de comunicación de Tartagal para con los pueblos originarios. La manera, el contenido y la organización existente en torno a la comunicación comunitaria indígena fueron los indicadores de una práctica política de transformación social. En este aspecto, "hablar como lo que se es" establece una relación directa con la identidad étnica. Para los sujetos indígenas de la radio, la identidad es una cualidad, un rasgo de origen, una vivencia y una posición estratégica a través de la cual reivindican la diferencia a la vez que impugnan a una sociedad local que los niega y discrimina.

En tanto territorio fecundo de luchas y tensiones, la comunicación comunitaria indígena constituye una práctica de ciudadanía que impugna el rol colonial del propio Estado. Se evidencia, de esta manera, un modo particular de apropiación del sentido de ciudadanía, que se asume desde el derecho, pero con el propósito de destruir el rol moderno y ordenador estatal, proponiendo así, transmutar y resignificar las luchas contra la conquista, expresadas, fundamentalmente, en las demandas que exigen la devolución de los territorios indígenas. 


\section{Referencias bibliograficas}

Agurto, J., y Mescco, J. (2012). La comunicación indígena como dinamizadora de la comunicación para el cambio social. XI Congreso Latinoamericano de Investigadores en Comunicación. Montevideo: ALAIC. Recuperado de https://www.servindi.org/pdf/ALAIC comunicaci\%C3\%B3nindigena2012.pdf

ARETEDE. (2020). Historia comunitaria de Yariguarenda. Tartagal: Fondo Editorial ARETEDE.

Baranchuk, M. (2011). Una ley para la democracia. En M. Baranchuk, y J. Rodríguez Usé (Coord.) Ley 26.522. Hacia un nuevo paradigma en comunicación audiovisual (págs. 6-12). Lomas de Zamora: Universidad Nacional de Lomas de Zamora.

Barranquero, A., y Sáez, C. (2015). Comunicación y buen vivir. La crítica descolonial y ecológica a la comunicación para el desarrollo y el cambio social. Palabra clave, 18(1), 41-82. Recuperado de http://www.scielo.org.co/pdf/pacla/v18n1/v18n1a03.pdf

Becker, H., \& Geer, B. (1982). Participant observation: the analysis of qualitative field data. En R. Burgess, Field Research: a sourcebook and field manual (pp. 239-250). Londres: George Allen and Unwin.

Buliubasich, C., y González, A. (2009). Los Pueblos Indígenas de la Provincia de Salta. La Posesión y el Dominio de sus Tierras. Departamento San Martín. Salta Capital: Centro Promocional de las Investigaciones en Historia y Antropología (CEPIHA)-Universidad Nacional de Salta.

Castro Gómez, S. (2000). Ciencias sociales, violencia epistémica y el problema de la invención del otro. En CLACSO, La colonialidad del saber: eurocentrismo y ciencias sociales. Perspectivas latinoamericanas. (págs. 88-98). Buenos Aires: Consejo Latinoamericano de Ciencias Sociales.

CCAIA (2011). Comunicación con Identidad. Aportes para la construcción del modelo de la comunicación indígena en Argentina. Buenos Aires: INAI. 
Cerbino, M., y Belloti, F. (2016). Medios comunitarios como ejercicio de ciudadanía: experiencias desde Argentina y Ecuador. Comunicar, 24(47), 49-56. Recuperado de https://www.revistacomunicar.com/index.php?contenido=detalles\&numero=47\&articulo=47$\underline{2016-05}$

Doyle, M. (2013). Los medios masivos de comunicación en las luchas de los pueblos indígenas. Abordaje desde los estudios sobre comunicación en América Latina. (Tesis de maestría).

Foucault, M. (1980). Microfísica del poder. Madrid: Las ediciones de La Piqueta.

Foucault, M. (2000). Defender la Sociedad. Curso en el Collège de France (1975-1976).

Buenos Aires: Fondo de Cultura Económica de Argentina. (Año de publicación del original, 1997).

Foucault, M. (2010). Nacimiento de la Biopolítica. Curso en el Collège de France (1978-1979). Buenos Aires: Fondo de Cultura Económica. (Año de publicación del original, 2004).

Graziano, M. (1980). Para una definición alternativa de la comunicación. Revista ININCO (1), 1 6.

Guber, R. (2011). La etnografía: Método, campo y reflexividad. Buenos Aires: Siglo XXI Editores.

Hammersley, M., \& Atkinson, P. (1994). Etnografía. Métodos de investigación. Barcelona: Paidós Ibérica.

Herrera Huérfano, E., Sierra Caballero, F., y Del Valle Rojas, C. (2016). Hacia una Epistemología del Sur. Decolonialidad del saber/poder informativo y nueva Comunicología Latinoamericana. Una lectura crítica de la mediación desde las culturas indígenas. Chasqui. Revista Latinoamericana de Comunicación (131), 77-105. Recuperado de https://dialnet.unirioja.es/servlet/articulo?codigo $=5792037$

Iñigo Carreras, N. (2010). Génesis, Formación y Crisis del Capitalismo en el Chaco 1870-1970. Salta: Editorial de la Universidad Nacional de Salta. 
Kejval, L. (2009). Truchas. Los proyectos político-culturales de las radios comunitarias, alternativas y populares argentinas. Buenos Aires: Prometeo Libros.

Lamas, E., y Villamayor, C. (1998). Gestión de la radio comunitaria y ciudadana. Bogotá: AMARC.

Lizondo, L. (2015). Comunicación con identidad o comunicación comunitaria. El caso de la FM La Voz Indígena. (Tesis de Maestría). Recuperado de http://sedici.unlp.edu.ar/handle/10915/50419

Martini, E. (2000). Periodismo, noticia y noticiabilidad. Buenos Aires: Editorial Norma.

Mata, M. C. (1993). La radio: una relación comunicativa. Diálogos de la Comunicación, 10-13.

Mata, M. C. (2002). Comunicación, Ciudadanía y Poder. Pistas para pensar su articulación. Diálogos de la Comunicación, 64-75.

Mata, M. C. (2006). Comunicación y ciudadanía. Problemas teoríco-políticos de su articulación. Fronteiras-Estudos midiáticos, 8 (1), 6-15.

Mata, M. C. (2009). Comunicación comunitaria en pos de la palabra y la visibilidad. En Area de Comunicación Comunitaria- UNNER, Construyendo comunidades: reflexiones actuales sobre la comunicación comunitaria (págs. 22-34). Buenos Aires: La Crujía.

Mata, M. C. (2011a). Comunicación y Ciudadanía: Dilemas Pendientes. En B. Alem, \& A. Arneigeiras (Comp.), Culturas populares y culturas masivas. Los desafíos actuales a la comunicación (pp. 1-11). Buenos Aires: Prometeo.

Mata, M. C. (2011b). Comunicación popular: continuidades, transformaciones y desafios. Oficios Terrestres, 1-22.

Pojasi, A. (2013). Tartagal, Salta, República Argentina. Sus orígenes y demarcaciones de límites (1864-1925). Salta: Fondo Editorial Secretaría de Cultura de la Provincia de Salta.

Rioja, L. (1997). Tartagal y el Norte del Bermejo (tierra olvidada). Apuntes, Crónicas y Relatos sobre su Historia y Geografía. Tartagal: 3L Ediciones. 
Restrepo, E. (2008). Cuestiones de método. Eventualización y problematización en Foucault. Tabula Rasa (8), 111-132. Recuperado de http://www.scielo.org.co/pdf/tara/n8/n8a06.pdf

BIBLIOGRAPHY Im Sán10 V 11274 Sánchez Amaya, T. (2010). La caja de herramientas como opción metodológica. Análisis (76), 71-102. Recuperado de https://www.redalyc.org/pdf/5155/515552365003.pdf BIBLIOGRAPHY Im Bec82 V| 11274

BIBLIOGRAPHY Im Sto101 V 11274 Stoler, A. L. (2010). Archivos coloniales y el arte de gobernar. Revista Colombiana de Antropología, 46(2), 465-496. Recuperado de https://www.redalyc.org/pdf/1050/105020003009.pdf

BIBLIOGRAPHY Im Vin14 V 11274 Vinelli, N. (2014). Comunicación alternativa: Ni dogma ni pureza, conflicto. Ponencia presentada al XVI Congreso de la Red de Carreras de Comunicación Social y Periodismo REDCOM "Nuevas configuraciones de la cultura en lenguajes, representaciones y relatos", Universidad Nacional de La Matanza, Buenos Aires. Recuperado dehttps://es.scribd.com/document/364148267/Comunicacion-Alternativa-NiDogma-Ni-Pureza-Conflicto

Vinelli, N., y Rodríguez Esperón, C. (2008). Contrainformación. Medios alternativos para la acción política. Buenos Aires: Dario Vive.

BIBLIOGRAPHY $\backslash \mathrm{m}$ Bar111 || 11274

\section{Notas}

(1) Para escuchar el documental radiofónico https://soundcloud.com/user-209132697/historiade-yariguarenda?si=d97be60c98294b1491820e75fe6f2a14

(2) Para escuchar el audio seguir el siguiente enlace https://soundcloud.com/user209132697/discurso-de-nl-desalojo-quebracho?si=0052055719a64f64ad8f4a8b6b5112fd 